\title{
ANÁLISE CRÍTICA DA NARRATIVA DE CURSOS MASSIVOS ABERTOS (MOOC): O CASO DO TELELAB
}

\section{CRITICAL ANALYSIS OF THE MASSIVE OPEN ONLINE COURSES NARRATIVE: THE CASE OF TELELAB}

\author{
Breno Biagiotti ${ }^{1}$, M.Sc. \\ Maria José Baldessar², D.Sc. \\ Vânia Ulbricht ${ }^{3}$, D.Sc. \\ Luciane $\mathrm{Fadel}^{4}$, D.Sc. \\ (1) Universidade Federal de Santa Catarina \\ e-mail: breno.biagiotti@posgrad.ufsc.br \\ (2) Universidade Federal de Santa Catarina \\ e-mail: $\underline{\text { mbaldessar@gmail.com }}$ \\ (3) Universidade Federal de Santa Catarina \\ e-mail: vrulbricht@gmail.com \\ (4) Universidade Federal de Santa Catarina \\ e-mail: luciane.fadel@ufsc.br
}

Palavras-chave: narrativa, MOOC, aprendizagem personalizada

Este artigo tem como proposta analisar a narrativa utilizada no MOOC Telelab, observando sua estrutura, linguagem e design instrucional. Considera-se que MOOC é uma nova mídia e, por isso, ainda está em busca de um formato que alinhe as propostas pedagógicas e os aspectos tecnlógicos. O foco da análise (que utilizou a metodologia close reading) priorizou os tipos aprendizagem, preferências dos usuários e os aspectos narrativos (sob a lente teórica de Marie-Laure Ryan). Apesar de ser um curso massivo, que capacita milhares de pessoas simultaneamente, a oferta de narrativas personalizadas, que considerem os diferentes perfis de alunos, pode ser um fator decisivo para a consolidação desses cursos no cenário educacional. Observou-se que o Telelab, mesmo não sendo um MOOC interativo, cumpre o que promete, disponibilizando cursos com linguagem acessível e apropriada para a capacitação de profissionais de saúde, utilizando uma narrativa que prioriza os exemplos e o desenvolvimento de habilidades práticas.

Keywords: narratives, $M O O C$, personalized learning

This article aims to analyze the narrative used in the MOOC Telelab, observing its structure, language and instructional design. It is considered that the MOOC is a new media and, therefore, is still in search of a format that aligns the pedagogical proposals and the technological aspects. The focus of the analysis (using the close reading methodology) prioritized learning types, user preferences and narrative aspects (under the theoretical lens of Marie-Laure Ryan). Although it is a massive course that trains thousands of people simultaneously, the provision of personalized narratives that take into account the different profiles of students can be a decisive factor for the consolidation of these courses in the educational scenario. It was observed that Telelab, even though it is not an interactive course, fulfills what it promises, providing courses with accessible and appropriate language for the qualification of health professionals, using a narrative that prioritizes the examples and pratical habilities. 


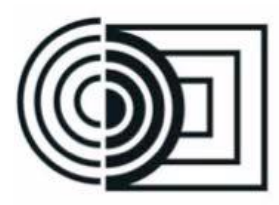

$16^{\circ}$ Ergodesign - Congresso Internacional de Ergonomia e Usabilidade de Interfaces Humano Tecnológica: Produto, Informações Ambientes Construídos e Transporte

$16^{\circ}$ USIHC - Congresso Internacional de Ergonomia e Usabilidade de Interfaces Humano Computador

CINAHPA | 2017 - Congresso Internacional de Ambientes Hipermídia para Aprendizagem.

\section{Introdução}

Desde 2008, ano que surgiram os primeiros MOOC, o debate em torno desses cursos massivos vem gerando grandes repercussões na comunidade acadêmica, principalmente em meio aos pesquisadores de educação e novas tecnologias. Considerado por muitos como uma iniciativa revolucionária e inovadora, por seu caráter democrático de compartilhamento de conhecimento, os MOOC também vem sendo alvo de críticas pedagógicas, além de apresentarem altas taxas de evasão e dificuldades em estabelecer um modelo de negócio rentável e sustentável [Biagiotti, Baldessar \& Quevedo, 2016]. Fato é que, para se consolidar como uma alternativa viável, os provedores de conteúdos para MOOC precisam se reinventar e buscar alternativas para corrigir essas questões. Um dos principais pontos de crítica remete justamente ao aspecto pedagógico. Por apresentar um público-alvo abrangente e heterogêneo, os MOOC pecam na forma como disponibilizam seus conteúdos pois não levam em consideração as preferências e as formas peculiares como os alunos aprendem. Utilizam linguagens e narrativas padronizadas que acabam por desestimular os usuários, gerando as altas taxas de abandonos por falta de interesse. Não é difícil encontrar cursos massivos que são simplesmente aulas presenciais filmadas e disponibilizadas na web. Segundo [Reich, 2015], a próxima geração de pesquisas sobre MOOC necessita priorizar com mais atenção os fatores causais que promovam a aprendizagem dos alunos nesses cursos. O foco no aprendizado pode ser um fator de êxito dos MOOC se forem criadas propostas que cativem os estudantes, tanto no seu conteúdo, quanto na forma como ele é apresentado. Pierre Lévy ressalta: "Vemos atualmente o novo paradigma da navegação (oposto ao do curso) que se desenvolve nas práticas de levantamento de informações e de aprendizagem cooperativa no centro do ciberespaço. Isso mostra a via para um acesso ao conhecimento ao mesmo tempo massificado e personalizado" [Lévy P. , 1999, p. 170].

Entender as motivações dos estudantes, seu comportamento e suas percepções sobre os MOOC pode ser o passo inicial para começar a mudar esse paradigma. Zheng et al. [2015] entrevistaram 18 alunos que já cursaram algum tipo de MOOC e identificaram que são inúmeras as motivações que os levam a entrar em um curso, entretanto notaram alguns comportamentos predominantes em relação à maneira como esses alunos aprendem. Um grupo se comportava como se estivesse em uma sala de aula presencial, acessando o conteúdo semanalmente, assistindo os vídeos e realizando as atividades propostas e participando dos fóruns. $\mathrm{O}$ outro grupo utilizava os MOOC como uma ferramenta de busca para conhecimentos específicos. Não estavam preocupados em participar das atividades e nem mesmo concluir o curso para obter certificado. Há ainda aqueles que acessavam os MOOC para entretenimento e interação com outros alunos.

Com base no tipo de interação dos alunos nos MOOC, Hill[2016] estabeleceu uma categorização desses usuários: Fantasmas: realizam o cadastro no curso e aparecem esporadicamente; Observadores: realizam o cadastro, exploram o material disponível mas não realizam avaliações nem interações; Nãoconcluintes: acessam o material, participam de algumas atividades mas não concluem o curso; Participantes-passivos: assistem as aulas, realizam as tarefas, interagem com outros alunos mas não se envolvem muito; Participantes-ativos: alunos que planejam contribuir com o curso, assistem as aulas, fazem as lições, interagem com outros usuários e concluem o curso.

Nesse contexto, que envolve diferentes tipos de alunos, diferentes formas de aprendizagem e diferentes objetivos pedagógicos, fica difícil

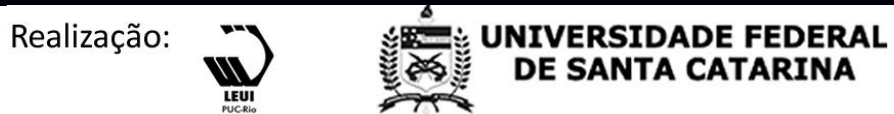




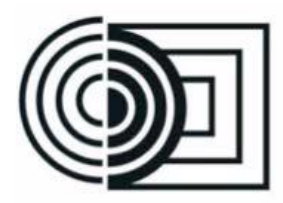

determinar diretrizes para a realização de um MOOC efetivo. Acredita-se que, analisando a estrutura e a experiência de um curso massivo específico, possa gerar alguma contribuição para esse cenário um tanto quanto difuso e carente de estudos empíricos. O objetivo desse artigo é realizar uma análise crítica do formato narrativo do MOOC Telelab, que disponibiliza diversos cursos abertos para profissionais da saúde.

\section{Revisão bibliográfica}

Para a produção desse artigo, realizou-se uma pesquisa bibliográfica sobre os seguintes temas e suas relações: MOOC, Learning cycles, learning preferences e narrativas para educação a distância. A figura 1 mostra a estrutura utilizada nessa pesquisa:

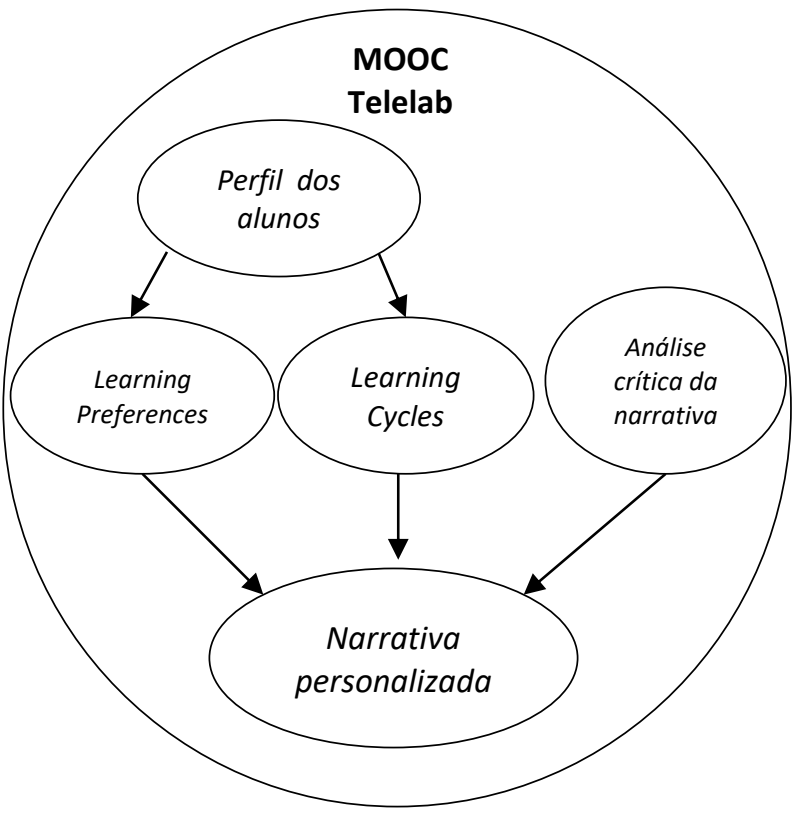

Figura 1 - Eixos temáticos dessa pesquisa

Fonte: elaboração do autor

Sobre os MOOC o foco foi em relação ao perfil dos alunos que utilizam esses cursos e a $16^{\circ}$ Ergodesign - Congresso Internacional de Ergonomia e Usabilidade de Interfaces Humano Tecnológica: Produto, Informações Ambientes Construídos e Transporte

$16^{\circ}$ USIHC - Congresso Internacional de Ergonomia e Usabilidade de Interfaces Humano Computador

CINAHPA | 2017 - Congresso Internacional de Ambientes Hipermídia para Aprendizagem. forma como são apresentados os conteúdos nessa plataforma. Optou-se pela análise do MOOC Telelab por ser uma iniciativa brasileira que vem obtendo excelentes resultados e expressivo número de certificação, além da facilidade de acesso aos dados educacionais gerados pelos alunos dessa plataforma que embasaram o estudo. A preocupação com a personalização da oferta do conteúdo dos MOOC vem sendo estudada também por um grupo de pesquisadores australianos, que propõe um framework baseado em um modelo personalizado de aprendizado, através da utilização de micronarrativas ${ }^{1}$. Segundo Sun[2015], essa forma de apresentar o conteúdo dos MOOC em partes menores vem se popularizando pois atende as demandas pessoais dos alunos em tempo real. Eles utilizaram um software que analisa a Big Data educacional e realiza a mineração dos dados para reconhecer o comportamento dos alunos, identificando potenciais formas de gerar micronarrativas através de técnicas da engenharia do conhecimento. Dessa forma o aluno pode realizar uma atividade, mesmo que em um espaço pequeno de tempo, e conseguir uma boa assimilação do conteúdo.

No âmbito pedagógico, buscou-se na literatura as abordagens utilizadas para internalização do conhecimento, através dos ciclos de aprendizagem, sob um contexto construtivista. Existem diversas teorias e a produção acadêmica é extensa nessa área. Dessa forma, optou-se pela análise dos MOOC sob a lente do ciclo proposto por Tsai e Lee [2006], que divide o processo de formação do conhecimento em quatro tipos:

- Criatividade auto-motivada (importar-se porquê) - experiências concretas 


\section{$16^{\circ}$ \\ ERGODESIGN USIHC CINAHPA}

- Compreensão dos sistemas (saber o porquê) - reflexão ou observação.

- Competências avançadas (saber como) experimentação ativa ou conceitos de teste em situações reais.

- Conhecimento cognitivo (saber o quê) conceptualização abstrata ou formação de conceito.

A Figura 2 mostra as etapas da do ciclo de aprendizagem de Tsai e Lee [2006].

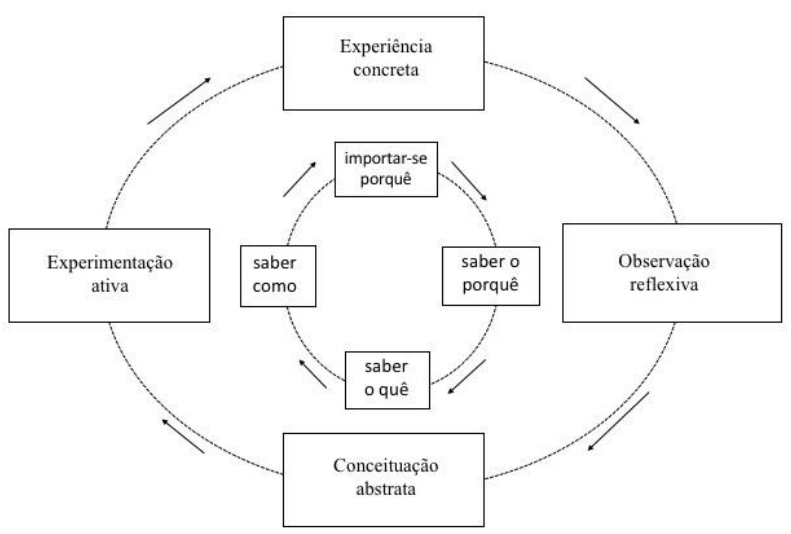

Figura 2 - Ciclo de Internalização do conhecimento. Tradução do autor

Corroborando essa definição e facilitando o entendimento das formas de comportamento dos domínios da aprendizagem, Anderson e Krathwohl [2001] categorizaram da seguinte forma: domínio cognitivo (aquisição de conhecimento e habilidades intelectuais); domínio afetivo (integração de crenças e ideias) e domínio psicomotor (aquisição de habilidades físicas e manuais). Aliando esses conceitos, pode-se ter uma noção, ainda que básica, que existem várias formas de se aprender e que isso deve ser levado em consideração na hora de elaborar os MOOC.

Sobre as preferências de aprendizagem, elas podem ser entendidas como o gosto dos estudantes por certos elementos de aprendizagem e a escolha dos caminhos de interação como esses elementos. Existem $16^{\circ}$ Ergodesign - Congresso Internacional de Ergonomia e Usabilidade de Interfaces Humano Tecnológica: Produto, Informações Ambientes Construídos e Transporte

$16^{\circ}$ USIHC - Congresso Internacional de Ergonomia e Usabilidade de Interfaces Humano Computador

CINAHPA | 2017 - Congresso Internacional de Ambientes Hipermídia para Aprendizagem. alunos que preferem aprender por texto, por vídeo, por áudio, através de exemplos, completando objetivos ou até mesmo realizando tarefas. A literatura no campo das preferências de aprendizagem geralmente cai em duas categorias: uma que se preocupa com os ambientes de aprendizado e os formatos instrucionais e outra que aborda os caminhos das atividades cognitivas. Neste artigo priorizou-se a primeira categoria, pois o foco é a análise dos ambientes e recursos utilizados na construção narrativa dos cursos massivos, especialmente no caso do Telelab.

Com objetivo de criar um MOOC que suportasse múltiplos estilos de aprendizagem, Gruenewald [2013] aplicou um questionário em cerca de 1200 alunos e sumarizou os principais tópicos com sugestões que poderiam implementar esses cursos:

- Consistência: usuários demonstraram insatisfação quando foram apresentadas definições contraditórias, imprecisas ou atividades sem contexto.

- Multimídia: usuários sugeriram cursos que fossem além dos formatos tradicionais, com maios utilização de recursos visuais como animações e simulações.

- Hipertexto: recomendaram maior utilização de links que permitiam a descoberta de novos recursos na internet.

- Comunicação síncrona: usuários demonstraram a necessidade de uma comunicação mais imediata, através de chats privados ou em grupo.

- Relevância prática: revelaram a importância da utilização de mais exemplos práticos e exercícios que incentivassem a investigação dos alunos.

Para a análise crítica do formato narrativo do Telelab utilizou-se os conceitos teóricos propostos por Marie-Laure Ryan, pesquisadora suíça autora de vasta literatura na área da narratologia e cibercultura, especialista em 


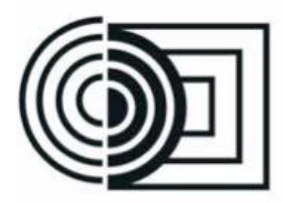

como as novas mídias influenciam a narratividade. Segundo definição da própria autora:

\author{
Narrativa é definida como \\ uma imagem mental, ou \\ construto cognitivo, que \\ pode ser ativado por vários \\ tipos de signos. Essa \\ imagem consiste em um \\ mundo, povoado por agentes \\ inteligentes. Esses agentes \\ participam de ações $e$ \\ acontecimentos que causam \\ uma mudança global no \\ mundo narrativo
}

[Ryan, 2004 p.337].

Ryan ressalta que o conceito de narrativa é bastante abstrato e flexível, pois tolera uma série de variações. Em linhas gerais, a narrativa forma os elementos principais da contagem de uma história e esse conceito pode ser aplicado em diversas mídias e contextos. Nesse artigo considera-se o MOOC como a mídia e o design instrucional aplicado nos cursos como o formato narrativo. Analisando dessa forma, pode-se considerar os recursos midiáticos (vídeo, texto, áudio, animações) como os agentes que, dependendo como são utilizados, geram mudanças no enredo do curso (pedagogia), levando aos possíveis finais (níveis de aprendizado). Ao longo da análise do Telelab esses conceitos ficarão mais evidentes. Primeiramente é necessário entender que existem vários modos narrativos, que não são excludentes e que podem ser combinados para uma melhor compreensão do enredo. Ryan [2006] categorizou esses modos narrativos da seguinte forma:

- Externa / Interna: a narrativa é textualizada e pode ser criada a partir de signos / pode ser fruto da imaginação. $16^{\circ}$ Ergodesign - Congresso Internacional de Ergonomia e Usabilidade de Interfaces Humano Tecnológica: Produto, Informações Ambientes Construídos e Transporte

$16^{\circ}$ USIHC - Congresso Internacional de Ergonomia e Usabilidade de Interfaces Humano Computador

CINAHPA | 2017 - Congresso Internacional de Ambientes Hipermídia para Aprendizagem.
- Ficcional / Não ficcional: a narrativa pode ser sobre algo inventado ou real.

- Representacional / Simulativa: um processo pode derivar diversas consequências, de acordo com o estado do mundo ou pode ser por um algoritmo que gera diferentes caminhos de acordo com parâmetros estipulados (narrativa para jogos).

- Diegética / Mimética: se faz uso de um narrador para contar a história ou utiliza-se a interpretação (narrativa de cinema, teatro, dança...).

- Autotélica / Utilitária: a história é simplesmente contada, sem grandes objetivos ou ela é contada com um objetivo principal de motivação, convencimento, explicação por exemplos.

- Autônoma / Ilustrativa: o texto transmite uma nova história ou ele reconta uma história já conhecida, requerendo do receptor um conhecimento prévio sobre o assunto.

- Scripted / Emergente: a narrativa é contada a partir de um texto previamente estipulado ou ele é improvisado na hora.

- Receptivo / Participativo: o receptor somente recebe a narrativa, sem o poder de alterar os eventos / ele pode participar e alterar a narrativa.

- Determinado / Indeterminado: o texto determina um suficiente número de pontos para formar um script / o receptor recebe poucos pontos e precisa imaginar como se concretiza o arco narrativo.

- Retrospectiva / Simultâneo / Prospectivo: narrativa de eventos passados / eventos presentes / eventos futuros (profecias).

- Literal / Metafórica: corresponde completamente a definição de narrativa / apresenta graus de narratividade variado, utilizando elementos de vários modos narrativos.

Outro constructo importante é o conceito de narratividade, que pode ser mensurado e que, 


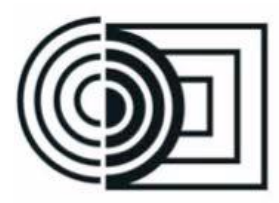

se for bem estruturado, tende a enriquecer a qualidade da narrativa. Ryan [2006] os divide em 4 dimensões:

- Dimensão espacial: A narrativa precisa abranger um mundo onde existam indivíduos.

- Dimensão Temporal: Esse mundo precisa estar situado no tempo.

- Dimensão Mental: Alguns indivíduos precisam ser inteligentes e reagirem emocionalmente às mudanças de estado desse mundo e suas ações devem seguir um plano identificável.

- Dimensão formal e pragmática: toda a sequência de eventos deve apresentar um fechamento, além de comunicar algo significativo para o receptor.

Ryan [2006] também ressalta outro fator importante a ser considerado na análise narrativa: a interatividade, que pode ser dividida nas seguintes categorias:

- Interna: o usuário possui uma perspectiva em $1^{a}$ pessoa.

- Externa: o usuário tem uma visão ampla e controle de navegação.

- Exploratória: o usuário tem liberdade para interagir, mas não altera o enredo.

- Ontológica: as decisões do usuário alteram o enredo.

Essa gama de conceitos apresentados formam o eixo teórico deste artigo, servindo de base para a análise crítica do MOOC Telelab, que será aprofundada nos capítulos a seguir.

\section{Objeto de análise}

O Telelab é um programa de educação continuada a distância do Ministério da Saúde em parceria com a UFSC (Figura 3) e tem como objetivo capacitar profissionais para a

\footnotetext{
2 Foi aplicada nos gestores e alunos a escala SERVQUAL, que varia
} gradativamente de 1 a 5 . A nota média obtida pelo Telelab foi de 4,5, $16^{\circ}$ Ergodesign - Congresso Internacional de Ergonomia e Usabilidade de Interfaces Humano Tecnológica: Produto, Informações Ambientes Construídos e Transporte

$16^{\circ}$ USIHC - Congresso Internacional de Ergonomia e Usabilidade de Interfaces Humano Computador

CINAHPA | 2017 - Congresso Internacional de Ambientes Hipermídia para Aprendizagem.

realização do diagnóstico de doenças sexualmente transmissíveis e AIDS. No ar desde 2012, já certificou aproximadamente 86 mil alunos em todo o país. Seu formato foi concebido para ser um MOOC, pois precisa atender uma demanda crescente de profissionais que atuam no Sistema Único de Saúde (cerca de 2500 novos alunos por mês), por isso são cursos gratuitos, abertos e massivos.

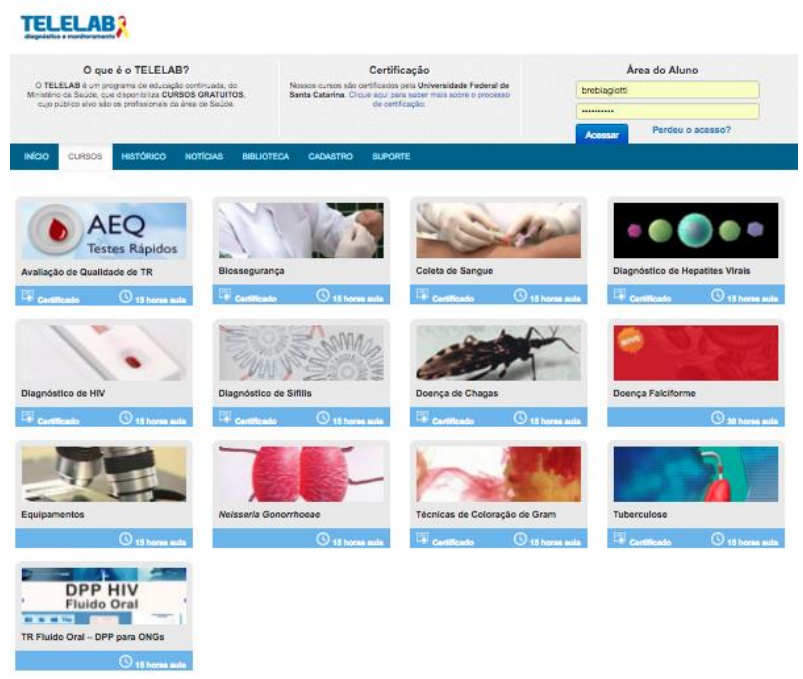

Figura 3 - Página de cursos do Telelab.

Fonte: www.telelab.aids.gov.br

Em entrevista realizada com 1201 usuários do curso $^{2}$, questionados acerca da qualidade das informações contidas no Telelab, evidenciouse o alto grau de satisfação, em especial em relação ao material instrucional. Em uma escala de 1 a 5 , o Telelab alcançou nota média de 4,5 , conforme mostra a figura 4 :

o que demosntra que os cursos superaram as expectativas dos usuários em diversos quesitos.
Realização:

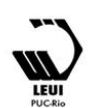




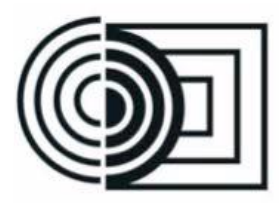

$16^{\circ}$ Ergodesign - Congresso Internacional de Ergonomia e Usabilidade de Interfaces Humano Tecnológica: Produto, Informações Ambientes Construídos e Transporte

$16^{\circ}$ USIHC - Congresso Internacional de Ergonomia e Usabilidade de Interfaces Humano Computador

CINAHPA | 2017 - Congresso Internacional de Ambientes Hipermídia para Aprendizagem.

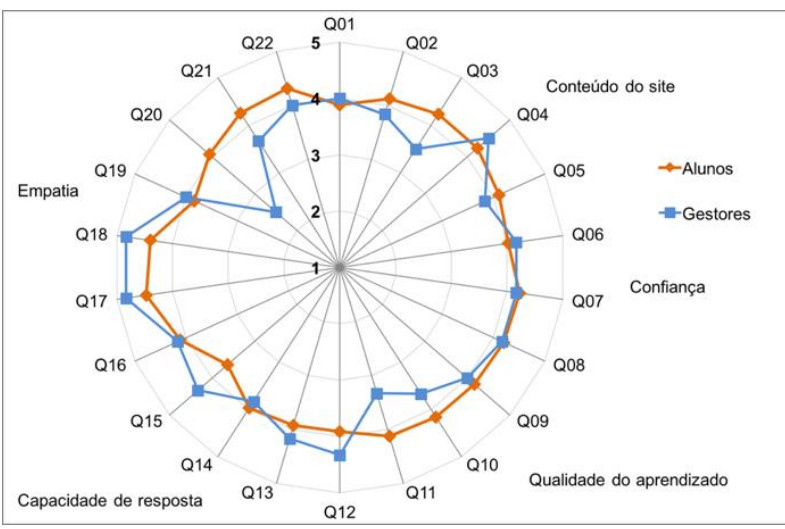

Figura 4 - Resultados da aplicação da escala Servqual. Fonte: Biagiotti [2015]

O Telelab se enquadra na categoria de cursos massivos instrucionais (cMOOC), utilizando basicamente vídeos e manuais e hyperlinks, com grande ênfase no desenvolvimento do conhecimento procedural, ou seja, ensinar os alunos a realizarem uma tarefa prática. Quadro 1 mostra as diferenças entre os formatos de MOOC que existem atualmente:

\begin{tabular}{|l|l|l|}
\hline \multicolumn{1}{|c|}{ xMOOCs } & \multicolumn{1}{c|}{ cMOOCs } \\
\hline $\begin{array}{l}\text { Escalabilidade de } \\
\text { oferta }\end{array}$ & Massivo & $\begin{array}{l}\text { Comunidades e } \\
\text { conexões }\end{array}$ \\
\hline $\begin{array}{l}\text { Acesso aberto } \\
\text { licença restrita }\end{array}$ & Aberto & $\begin{array}{l}\text { Acesso e licença } \\
\text { aberta }\end{array}$ \\
\hline $\begin{array}{l}\text { Aprendizado } \\
\text { individual em única } \\
\text { plataforma. Uso de } \\
\text { vídeos, manuais e } \\
\text { resolução de } \\
\text { problemas. }\end{array}$ & Online & $\begin{array}{l}\text { Aprendizado em rede } \\
\text { através de múltiplas } \\
\text { plataformas e serviços } \\
\text { (blogs, posts, } \\
\text { imagens, diagramas e } \\
\text { vídeos) }\end{array}$ \\
\hline $\begin{array}{l}\text { Adquirir } \\
\text { conhecimentos e } \\
\text { habilidades para o } \\
\text { currículo. Avaliação } \\
\text { e certificados. }\end{array}$ & Curso & $\begin{array}{l}\text { Desenvolver práticas } \\
\text { compartilhadas, } \\
\text { conhecimento e } \\
\text { compreensão }\end{array}$ \\
\hline
\end{tabular}

Quadro 1 - Diferenças entre formatos de MOOC. Fonte: adaptado Yuan et al. [2014]

\section{Método}

Para a execução desse artigo utilizou-se o método Close Reading (CR), que consiste em uma leitura aprofundada e bem interpretada de partes de um texto. Esse método é uma técnica analítica muito utilizado por críticos em geral, que prioriza um conteúdo específico em relação ao todo. É um processo de desmembramento em busca dos significados que não estão evidentes. Jacques Fontanille [1999] argumenta que existem duas formas de analisar o texto: como um objeto (elemento material e instrucional) ou como uma unidade discursiva (coerente com a interpretação inerente do leitor. Ainda segundo o autor, a análise crítica de uma mídia eletrônica, utilizando o método $\mathrm{CR}$, "deve ser lenta, com muito esforço, continuamente avançando e retrocedendo, não apenas clicando e navegando randomicamente". Dessa forma, buscou-se analisar a estrutura narrativa do Telelab, sua linguagem e a maneira como seu conteúdo foi formatado para os alunos, através dos conceitos de narrativa propostos por [Ryan, 2004 e 2006]. Nessa análise crítica também foram observados os aspectos pedagógicos e as preferências dos alunos, pois acredita-se que uma narrativa apropriada deve levar em conta o perfil do aluno e como ele assimila melhor os conteúdos.

\section{Resultados}

Inicialmente, analisou-se o Telelab de acordo com as propriedades das novas mídias (Quadro 2), segundo Ryan [2004].

\begin{tabular}{ll}
\hline \multicolumn{1}{c}{$\begin{array}{c}\text { Propriedades da mídia } \\
\text { digital }\end{array}$} & \multicolumn{1}{c}{ Telelab } \\
\hline Natureza reativa e interativa & Poucos recursos interativos \\
$\begin{array}{l}\text { Múltiplos canais sensoriais e } \\
\text { semióticos }\end{array}$ & $\begin{array}{l}\text { Convergência multimídia } \\
\text { Uso de hipertexto, vídeo, } \\
\text { imagem e som. }\end{array}$ \\
& $\begin{array}{l}\text { É um AVA que permite grande } \\
\text { quantidade de alunos e } \\
\text { recursos ao vivo. }\end{array}$ \\
& $\begin{array}{l}\text { MOOCs podem ser compostos } \\
\text { por objetos de aprendizagem } \\
\text { (OA), Recursos Educacionais }\end{array}$ \\
& Abertos (REAs) \\
Modularidade &
\end{tabular}

Realização:

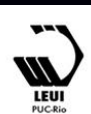




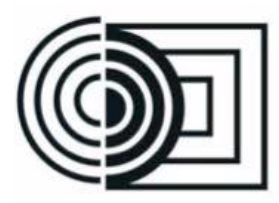

Quadro 2 - Propriedades das novas mídias presentes no Telelab.

Em relação ao perfil dos alunos, para compreender a linguagem utilizada pela equipe de criação dos cursos, faz-se necessário conhecer o público a que ela se destina. De todos os alunos cadastrados no site, $42,9 \%$ são estudantes; $36,5 \%$ são profissionais do SUS; $8,7 \%$ são profissionais liberais; $1,1 \%$ são professores e $10,8 \%$ são outros interessados. Quanto ao nível de escolaridade, predominam os que tem nível superior completo, seguidos pelos que tem nível médio e especialização ou MBA. Mestrado e doutorado são minoria nessa população.

Com esses dados, nota-se que o público é bastante heterogêneo, o que justifica a linguagem utilizada. Todos os cursos apresentam os conteúdos de maneira didática, evitando os termos técnicos e palavras muito difíceis. Os manuais em ".pdf" utilizam bastante imagens, ilustrações e fluxogramas. Conceitos importantes recebem destaque e diagramação diferenciada e com destaque. Utiliza-se bastante hyperlinks, direcionando para outros sites e para a indicação das bibliografias utilizadas. Pode-se encontrar constantemente instruções de passo-a-passo para ensinar os processos (Figura 5). $16^{\circ}$ Ergodesign - Congresso Internacional de Ergonomia e Usabilidade de Interfaces Humano Tecnológica: Produto, Informações Ambientes Construídos e Transporte

$16^{\circ}$ USIHC - Congresso Internacional de Ergonomia e Usabilidade de Interfaces Humano Computador

CINAHPA | 2017 - Congresso Internacional de Ambientes Hipermídia para Aprendizagem.

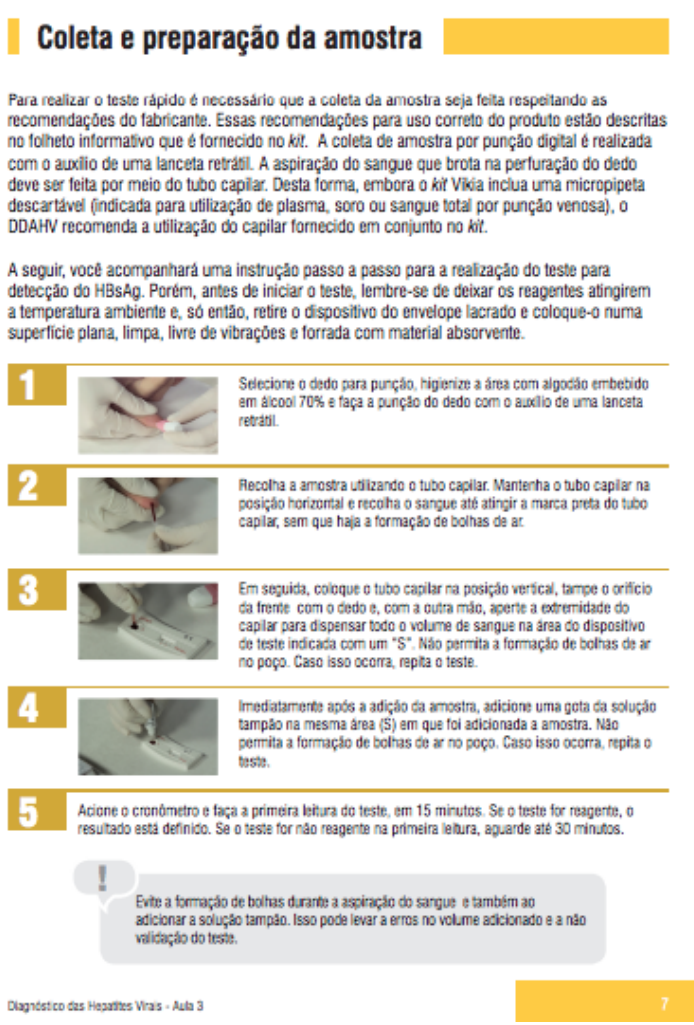

Figura 5 - Instruções numeradas e com imagens. Fonte: Telelab

Os Manuais são divididos de acordo com o número de aulas do curso. Dessa forma, o conteúdo raramente ultrapassa 15 páginas. Isso mostra a tendência em produzir materiais que possam ser rapidamente lidos quando necessário, ou seja, pequenas unidades de aprendizagem, que fazem parte de um todo. O conteúdo de todo o site é responsivo e se adapta ao dispositivo que o usuário está acessando. $81 \%$ dos alunos acessam através de computadores desktop, $16 \%$ acessam via smartphones e $3 \%$ via tablets. Essas facilidades resultam em um grande número de acessos (688 mil), sendo que desses, 57\% são usuários que retornam constantemente ao Telelab, seja para pesquisa ou consulta de materiais. 


\section{$16^{\circ}$ \\ ERGODESIGN \\ USIHC \\ CINAHPA}

$16^{\circ}$ Ergodesign - Congresso Internacional de Ergonomia e Usabilidade de Interfaces Humano Tecnológica: Produto, Informações Ambientes Construídos e Transporte

$16^{\circ}$ USIHC - Congresso Internacional de Ergonomia e Usabilidade de Interfaces Humano Computador

CINAHPA | 2017 - Congresso Internacional de Ambientes Hipermídia para Aprendizagem.
Além dos manuais, as videoaulas são o recurso mais acessado pelos alunos. Ao todo já somam mais de 715 mil visualizações no youtube.

A linguagem acessível e objetiva é facilitada pelos apresentadores reconhecidos nacionalmente (Figura 6)

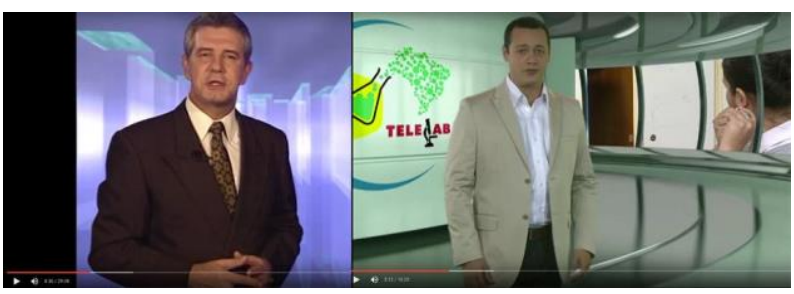

Figura 6 - Celso Freitas e Danton Melo apresentando as videoaulas. Fonte: Telelab.

O vídeo é uma poderosa mídia para capacitação, ainda mais quando o objetivo é ensinar através de exemplos. Todos os procedimentos são filmados em detalhes e explicados minuciosamente, repetindo quando necessário. Essas videoaulas também são divididas em partes menores, para facilitar o acesso dos alunos que, em média, dura 5 minutos.

Sob o aspecto pedagógico, buscou-se enquadrar o Telelab no ciclo de internalização do conhecimento proposto por Tsai e Lee [2006], mostrado na figura 2. A experimentação ativa e concreta, inerentes do conhecimento procedural, se destacam. Deseja-se que o aluno aprenda a realizar os procedimentos, assim como desenvolva a consciência da importância de realizar esse trabalho. Exemplificando: os alunos precisam aprender a realizar os testes rápidos para DSTs com eficiência, além de saberem da disseminação dessas doenças.

Para abranger as preferências dos usuários, os conteúdos das aulas podem ser acessados de 3 formas: online, diretamente no site; em DVDs que são enviados sem custo para os alunos (cerca de 3 mil já enviados), além da opção de baixar todo o conteúdo zipado, para assistir offline. Esse aspecto inclusivo favorece as pessoas que não tem acesso a internet banda larga. Entretanto essa é o único recurso inclusivo dos cursos, uma vez que eles não são acessíveis para deficientes visuais e auditivos e não são legendados. Os cursos também não apresentam nenhuma possibilidade de interatividade e interação entre os alunos. Não há chats nem possibilidade síncrona de comunicação. Dúvidas e sugestões são feitas somente por email, o que deixa o suporte ao aluno um pouco demorado.

De acordo com as definições de Ryan [2006] acerca da interatividade, a narrativa do Telelab se enquadra como interna e exploratória. $\mathrm{O}$ aluno está por sua conta no ambiente virtual de aprendizagem, pode acessar os recursos conforme desejar, mas não tem poder de alterar a proposta pedagógica. $\mathrm{O}$ design instrucional do curso proporciona um caminho linear para alcançar os objetivos propostos. Ao contrário dos cMOOC, o aluno não tem como agregar conhecimento ao curso, uma vez que não participa de fóruns e chats com outros alunos.

Pode-se considerar que o Telelab apresenta um valor mediano de narratividade, se considerarmos as dimensões de Ryan: os alunos formam o público-alvo (dimensão espacial), que estão atuando em suas respectivas funções neste presente momento (dimensão temporal) e precisam realizar com precisão o diagnóstico do maior número de pessoas possíveis para conter a disseminação das doenças sexualmente transmissíveis no país (dimensão mental). Ao final, realizado o exame, os profissionais devem informar os pacientes se eles estão ou não infectados, além de acolhe-los e direciona-los para o tratamento adequado, mostrando a importância de realizar esses testes e não deixar a doença avançar, pois diminui as chances de tratamento (dimensão formal e pragmática). Esse é o
Realização:

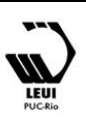

(3)




\section{$16^{\circ}$ \\ ERGODESIGN USIHC CINAHPA}

enredo base dos cursos, responsável pela qualificação dos profissionais de saúde.

Também realizou-se uma análise em relação ao modos narrativos utilizados no Telelab, segundo a teoria de Ryan [2006]. O uso de signos indica uma narrativa textualizada (externa), que aborda assuntos reais (não ficcional) e seus diversos desdobramentos (representacional). Os cursos são apresentados por um âncora, que utiliza recursos de narração para contar as histórias para os alunos (diegética), com objetivo claro de capacitá-los através da explicação de exemplos (utilitária). O conteúdo transmitido nas aulas requer um conhecimento prévio do aluno (ilustrativo) e segue um roteiro previamente definido (scripted), geralmente guiado pelas portarias ministeriais e fluxogramas de tratamento. Não há possibilidade de improvisação. Os alunos apenas recebem os conteúdos (receptivo) sem poder alterar os eventos. $\mathrm{O}$ modelo instrucional determina pontos suficientes para formar o enredo (determinado) e os acontecimentos são narrados no tempo presente (simultâneo), apresentando início, meio e fim bem definidos (literal). O Quadro 3 sumariza essa análise.

\begin{tabular}{|l|l|}
\hline \multicolumn{1}{|c|}{ Dimensões analisadas } & \multicolumn{1}{c|}{\begin{tabular}{c}
\multicolumn{1}{c|}{ Características presentes } \\
no Telelab
\end{tabular}} \\
\hline $\begin{array}{l}\text { Propriedades das novas } \\
\text { mídias }\end{array}$ & $\begin{array}{l}\text { Natureza reativa e interativa (pouco } \\
\text { aproveitada) } \\
\text { Múltiplos canais sensoriais e } \\
\text { semióticos } \\
\text { Capacidade de rede } \\
\\
\text { Sinais voláteis } \\
\text { Modularidade }\end{array}$ \\
\hline Modos Narrativos & Externo \\
& Não-ficcional \\
& Representacional \\
& Diegética \\
& Utilitária \\
& Ilustrativa \\
& Scripted \\
& Ilustrativa \\
& Receptiva \\
& Determinada \\
& Literal \\
\hline Interatividade & Interna e exploratória \\
\hline Narratividade & Moderada \\
\hline Internalização do & Criatividade auto-motivada \\
conhecimento & (importar-se porquê) - experiências \\
& concretas \\
\hline
\end{tabular}

$16^{\circ}$ Ergodesign - Congresso Internacional de Ergonomia e Usabilidade de Interfaces Humano Tecnológica: Produto, Informações Ambientes Construídos e Transporte

$16^{\circ}$ USIHC - Congresso Internacional de Ergonomia e Usabilidade de Interfaces Humano Computador

CINAHPA | 2017 - Congresso Internacional de Ambientes Hipermídia para Aprendizagem.

\begin{tabular}{|l|l|}
\hline & $\begin{array}{l}\text { Competências avançadas (saber } \\
\text { como) - experimentação ativa ou } \\
\text { conceitos de teste em situações reais. }\end{array}$ \\
\hline $\begin{array}{l}\text { Preferência de } \\
\text { aprendizagem }\end{array}$ & $\begin{array}{l}\text { Aprendizagem por texto } \\
\text { Aprendizagem por exemplo } \\
\text { Desenvolvimento psicomotor } \\
\text { conhecimento procedural }\end{array}$ \\
\hline
\end{tabular}

Quadro 3 - dimensões analisadas no Telelab.

\section{Conclusão}

Pensar em novas narrativas para a elaboração de cursos massivos pode ser uma tarefa desafiadora, uma vez que os MOOC não possuem um público-alvo definido. Qualquer pessoa pode acessar os conteúdos livremente, então como é possível oferecer uma boa qualidade de ensino nesse contexto? Localizar os perfis de alunos pode ser o passo inicial, utilizando técnicas Learning Analytics, que busca padrões na Big Data Educacional gerada por esses cursos com finalidade de melhorar a aprendizagem dos alunos. Uma vez detectado esses perfis de usuários, pode-se direcionar ações específicas para cada grupo categorizado, oferecendo, dessa forma, um conteúdo com uma narrativa personalizada.

No caso do Telelab, os cursos apresentam narrativas simples e objetivas, priorizando uma linguagem acessível, com ênfase em vídeos e manuais. Os cursos não apresentam muitos recursos tecnológicos e interativos, mas são eficientes e bem aceitos pelo público. A proposta do Telelab parece agradar pela sua simplicidade. Desde o cadastro até a emissão do certificado, tudo foi projetado para ser intuitivo e descomplicado. Isso comprova que o sucesso de um curso não depende somente dos aspectos tecnológicos.

No aspecto pedagógico, percebe-se claramente a preocupação com a internalização do conhecimento procedural. A aprendizagem por exemplos tem conseguido bons resultados, mas seria interessante proporcionar games e simulações para fixação do conteúdo, tentando inserir elementos interativos na narrativa dos 


\section{$16^{\circ}$ \\ ERGODESIGN USIHC CINAHPA}

$16^{\circ}$ Ergodesign - Congresso Internacional de Ergonomia e Usabilidade de Interfaces Humano Tecnológica: Produto, Informações Ambientes Construídos e Transporte

$16^{\circ}$ USIHC - Congresso Internacional de Ergonomia e Usabilidade de Interfaces Humano Computador

CINAHPA | 2017 - Congresso Internacional de Ambientes Hipermídia para Aprendizagem. cursos. Isso pode ser útil, inclusive, para aumentar o engajamento de alunos e diminuir as taxas de evasão.

Analisando os perfis dos alunos do Telelab, notou-se dois grupos específicos: estudantes e profissionais da saúde. Para os estudantes poderia se pensar em uma narrativa com ênfase na pesquisa, com bastante sugestão de bibliografias e hyperlinks. Para os profissionais da saúde, a ênfase poderia ser nas simulações e na aplicação de exercícios com casos clínicos, simulando a rotina diária de atendimentos. Nos dois casos, os conteúdos devem ser divididos em unidades menores (micro aprendizagem) para facilitar o acesso dos alunos, que dificilmente realizam todo o curso em um único acesso. O sucesso dos cursos depende do equilíbrio entre os aspectos pedagógicos, tecnológicos e o profundo conhecimento do perfil do público ao qual o conteúdo se destina.

\section{Referências Bibliográficas}

BIAGIOTTI, B., BALDESSAR, M., \& QUEVEDO, S. R. Modelos de negócio na cibersociedade: o caso dos cursos massivos abertos online (MOOC). Em L. A. Tarcisio Vanzin, Cibersociedade: fragmentos $e$ reflexões. Erechin, RS, Brasil: Deviant, 2016.

FONTANILLE, J. "Préface", in Alain Vuillemin and Michel Lenoble (eds.), Littérature, Informatique, Lecture. De la lecture assistée par ordinateur à la lecture interactive. Limoges: Pulim, pp. I-VIII, 1999.

GRÜNEWALD, F., et al. "Designing MOOCs for the support of multiple learning styles." European Conference on Technology Enhanced Learning. Springer Berlin Heidelberg, 2013.

HILL, P. Emerging student patterns in moocs: a (revised) graphical view. 2013-03-10]. Http://mfeldstei n. Com/emerging- studentpatterns-in-moocs-a-revised-graphicalview, 2013.

KOVACHEV, D., et al. "learn-as-you-go: new ways of cloud-based micro-learning for the mobile web." international conference on web-based learning. Springer berlin heidelberg, 2011.

LÉVY. Cibercultura. São Paulo, Brasil: 34, 1999.

REICH, J. Rebooting MOOC research. Science , 347 (6217), pp. 34-35, 2015.

RYAN, M.-L. Avatars of Story. Minneapolis, MN, EUA: University of Minnesota Press, 2006.

RYAN, M.-L. Will new media produce new narratives. Em M.-L. Ryan, Narratives across media: The languages os storytelling ( $\mathrm{pp}$. 337-359). Nebraska: University of Nebraska Press, 2004.

SUN, G. C. Micro Learning Adaptation in MOOC: A Software as a Service and a Personalized Learner Model. In International Conference on Web-Based Learning (pp. 174184). Springer International Publishing. 2015.

TSAI, M.-T., \& LEE, K.-W. A study of knowledge internalization: from the perspective of learning cycle theory. Journal of Knowledge Management, 10(3), 57-71, 2006.

YUAN, L., POWELL, S., \& OLIVIER, B. Beyond MOOCs: Sustainable online learning in institutions. Cetis White paper. 2014. Disponível em: http://publications. cetis. ac. uk/2014/898. Acesso em 23 fev. 2016.

ZHENG, S., ROSSON, M. B., SHIH, P. C., \& CARROLL, J. M. Understanding student
Realização:

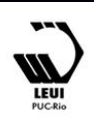




\section{$16^{\circ}$ \\ ERGODESIGN USIHC CINAHPA}

$16^{\circ}$ Ergodesign - Congresso Internacional de Ergonomia e Usabilidade de Interfaces Humano Tecnológica: Produto, Informações Ambientes Construídos e Transporte

$16^{\circ}$ USIHC - Congresso Internacional de Ergonomia e Usabilidade de Interfaces Humano Computador

CINAHPA | 2017 - Congresso Internacional de Ambientes Hipermídia para Aprendizagem.

motivation, behaviors and perceptions in MOOCs. Proceedings of the 18th ACM Conference on Computer Supported Cooperative Work \& Social Computing. Vancouver: ACM, 2015. 